\title{
Fifteen-minute consultation: Attachment as a model to understand and manage difficult doctor-parent relationships
}

\section{Annie Swanepoel}

Correspondence to

Dr Annie Swanepoel, Child and Adolescent Psychiatry, Elysium Healthcare Ltd, Borehamwood, WD6 1JN, UK; annie.panzer@ gmail.com

Received 5 June 2018 Revised 18 August 2018 Accepted 2 September 2018 Published Online First 28 September 2018

\section{Check for updates}

(c) Author(s) (or their employer(s)) 2019. No commercial re-use. See rights and permissions. Published by BMJ.

To cite: Swanepoel A. Arch Dis Child Educ Pract Ed 2019;104:178-182.

\begin{abstract}
Paediatricians are often faced with managing the child who is unwell, and parents, who may present in ways that are difficult to manage. Difficult behaviours can range from those who disregard their child's needs, to those who overstate their child's minor symptoms, to those who ask for help but then refuse to accept it. This paper gives a framework using attachment theory to help paediatricians recognise, understand and deal with difficult doctor-parent interactions in a way that is appropriate and sensitive. Making changes to the way we communicate with parents can improve outcomes for the child, the family and the doctor's own well-being.
\end{abstract}

\section{INTRODUCTION}

Attachment theory was first described by John Bowlby (see box 1). He developed this theory to describe the reactions that infants and children had when they were unwell and left in hospital. Bowlby was interested in animal behaviour and evolution and took the approach that humans are mammals and as such have an instinctive need for others' help and support when they are stressed or unwell. Attachment theory describes the different reactions that people exhibit when they feel vulnerable. In previous papers, I and others described how adults may respond in difficult ways when they are hospitalised and how doctors can change their approach in order to be most helpful. ${ }^{1-6}$ In this paper, I want to expand that theory to the feelings parents have when they need to seek help for a sick child. Having a sick child is a strong attachment stressor and will trigger parents to respond in a similar way they would respond if they were ill themselves.
In Attachment theory, four main categories are described. ${ }^{2}{ }^{4}$ Three of these are organised strategies and these were described by Bowlby: secure, insecure-avoidant (also called 'dismissive' in adults) and insecure-anxious (called 'preoccupied' in adults). A fourth category was later added by Mary Ainsworth, and this was typified by a lack of organisation and termed 'disorganised' (or 'fearful' in adults). I will describe each of these categories in turn to help readers recognise and understand these (see table 1 for a summary). Following this, the main adaptations in clinician manner will be described to facilitate the best outcomes.

\section{ATTACHMENT CATEGORIES}

Children use their primary relationship experience to extrapolate and create unconscious mental models of the world. This may be adaptive, as children learn to fit in with the environment that they are born into. ${ }^{4}$ However, a hospital or healthcare setting is a different environment from what children know from home. Also, doctors and nurses may not be like their parents at all. What was adaptive at home may be maladaptive in a healthcare setting.

\section{Secure}

A secure attachment develops when a child has a primary caregiver who is sensitive and responsive to the child's needs. These children grow up to believe that they are worthy of care and that others are able and willing to provide it. Approximately $50 \%$ of adults have a secure attachment style, either from having received good parenting when they were children or from becoming 'earned secure' later in life through a good experience such as therapy. Such adults are likely to also be 


\section{Box 1 Attachment theory}

- Attachment theory is a psychological theory that describes how humans respond when they are stressed, hurt, ill or threatened. The way that humans seek help depends on their experiences in early childhood. This may be adaptive, so that their style of help-seeking fits with what the environment is likely to provide.

sensitive and responsive to their own children. ${ }^{4}$ They believe that doctors and other staff are competent and do not have problems entrusting their sick children to professionals. Such families are generally easy to help, as they seek help appropriately and follow professional recommendations.

\section{Avoidant/Dismissive}

The second most common attachment style at around $25 \%$ of the general population is termed 'avoidant' in children and 'dismissive' in adults, although this varies between cultures and countries-for example, it is much more common in Germany and much less common in Japan. ${ }^{4}$ A child who has a primary caregiver who believes that children should be independent as soon as possible will grow up to learn that they need to fend for themselves and fulfil their own needs. Such children develop mental models of themselves as worthy of care, but others as unable or unwilling to help them. As adults, they are typically dismissive of close relationships and emotional support, as they believe that everyone is responsible for their own needs. Parents with a dismissive attachment style may not seek help in a timely way for their unwell child and may brush off any recommendations that the child needs tender loving care. They may feel that 'what doesn't kill you makes you stronger' and expect their children to be tough and stoic. Such parents can be difficult to deal with if they underestimate the seriousness of their child's illness and refuse to engage in treatment plans. Such parents may not give a child the medication as prescribed and be in denial about the severity of the child's condition.

\section{Anxious/Preoccupied}

About $15 \%$ of the population have an attachment style that is termed 'anxious' in children and 'preoccupied' in adults. ${ }^{4}$ Primary caregivers who fluctuate between giving in to the child's every whim and then feeling overwhelmed and distancing themselves have children who never know what to expect. These children know that their primary caregiver is able to give good and sensitive care, but they know that they cannot depend on it, as their primary caregiver is often emotionally unavailable or preoccupied with other things. Such children grow up believing that they need to give strong signals, like crying and clinging, to make sure that they get their primary caregiver's attention and care. When they grow up, their mental models of the world are that others are able to provide care but will do so only if pushed. Parents with this attachment style are often preoccupied with their own difficulties and not able to tune into their children's needs in a consistent manner. This leads to an intergenerational pattern of anxious attachment, with preoccupied parents and clingy, whining children. These parents believe that doctors and medical care are important and worthwhile, but they think that they need to really push in order to get the care their unwell child needs. Such parents can be experienced as difficult by doctors, as they ask for medication or interventions that are unnecessary. They are typically not easily comforted, if at all. They may request an inordinate amount of appointments for their child, and any reassurance that their doctor provides does not last for long before they want another appointment. They may also take the medication regimen into their own hands, giving medication too often, or irregularly and adding in other medication that was not prescribed to the child. These parents may be overly anxious and have an exaggerated idea of the seriousness of the child's presentation.

\section{Disorganised/Fearful}

The least common attachment style is found in 10\% of the general population and is termed 'disorganised' in children and 'fearful' in adults. This is by far the most common attachment style in patients in psychiatric clinics. ${ }^{4}$ Children who grow up with a primary caregiver who is frightening are faced with an unresolvable

\begin{tabular}{|c|c|c|c|c|}
\hline Attachment style in child & Attachment style in adult & Mental model of self & Mental model of other & Impression \\
\hline Secure. & Secure. & Worthy of care. & $\begin{array}{l}\text { Able and willing to provide } \\
\text { care. }\end{array}$ & Sensible, easy to help. \\
\hline Avoidant. & Dismissive. & Worthy of care. & Incapable of providing care. & Compulsively self-reliant. \\
\hline Anxious. & Preoccupied. & Worthy of care. & Unwilling of providing care. & Compulsively care-seeking. \\
\hline Disorganised. & Fearful. & Unworthy of care. & $\begin{array}{l}\text { Unwilling and/or incapable of } \\
\text { providing care. }\end{array}$ & $\begin{array}{l}\text { Help-seeking but rejecting of } \\
\text { help. }\end{array}$ \\
\hline
\end{tabular}

Different styles of attachment have been described, and although the categories are very similar between adults and children they have different names. 
dilemma. The natural instinct of children who are frightened is to turn to their primary caregiver for support. However, if the primary caregiver is also the source of the fear, it puts them in a situation where they are caught between wanting to flee and wanting to come closer to be soothed. This has been termed 'fear without solution' and can lead to children dissociating and being in a trance-like state. These children have been described as presenting with weird behaviours, for example approaching their primary caregiver while walking backwards, or approaching, but then hiding under their chair, or approaching and then retracing their steps, while being extremely vigilant. Children who grow up in an unpredictable and dangerous environment develop a mental model of themselves as unworthy of care and others as unable or unwilling to provide it. When such children become parents and they have not had a chance to work through their unresolved trauma, there is a higher likelihood that they will be abusive to their own children, as they never had an experience of good parenting. Also, a primary caregiver who is depressed or frightened herself would be experienced as frightening to a child, so that children can develop a disorganised attachment, even when there has not been any overt abuse. This is part of the intergenerational transmission of trauma. These families typically present the greatest difficulties to paediatricians and this is where psychological or psychiatric expertise can be enormously helpful.

In summary, parents with a fearful attachment style fluctuate in their caregiving to the child due to their own difficulties. Such children are typically frightened and tend to cry without being consoled by the parent. In more severe cases, children may be too scared to cry and keep a fearful watch on the parent's every move. Unfortunately, these children and parents are also deeply mistrustful of professionals, as they expect to be hurt or let down. These families are difficult to help, as they tend not to follow professional advice and are quick to be critical and make complaints or disengage.

\section{ATTACHMENT THEORY-INFORMED COMMUNICATION ADVICE}

First of all, it is important to make the point that patients are the way they are and we cannot expect them to adapt to suit the needs of the healthcare professional..$^{5}$ It is the professional's responsibility to be sensitive to the different communication needs patients have and to adapt accordingly. This can and should mean that the professional's style needs to vary, dependent on whom they are dealing with (see box 2 for a summary).

\section{Secure}

Securely attached parents and children are easy to work with, as they generally trust that doctors know what they are doing. They tend to be measured in
Box 2 Attachment theory-informed adaptations to communication styles for paediatricians

Securely attached families are unlikely to present with difficult behaviours and following standard practice is recommended.

- Avoidantly attached parents: The best way to deal with these 'compulsively self-reliant' parents is to treat them as equals and to keep the communication fact-based and unemotional. It can help to address them with title and surname and to give them printed information. Avoid an authoritarian attitude.

- Anxiously attached parents: Try to get out of the pattern where you see them after they ask for help, as this reinforces their idea that they need to crank up their 'compulsively care-seeking' behaviour in order not to be forgotten. The key is to offer pre-emptive regular, predictable contact (even if infrequent), so that they are reassured that they will get support without having to demand it. Letting families know when you will see them next and sticking to that will go a long way to reduce inappropriate help-seeking.

- Disorganised/fearful parents: The most effective way of coping with these very difficult families is to think of them as people who need help but cannot bring themselves to accept it. They feel vulnerable and do not feel able to trust others. Provide your usual good standard of care and create opportunities of staff to talk about this family, so that difficult feelings in staff are worked through, rather than acted out. Getting psychiatric/psychological input early, even if only to support staff in their thinking about the family, is ideal.

seeking help and they follow instructions. These patients are rarely experienced as 'difficult'. However, it is important to remember that they only make up about $50 \%$ of the general population and that it is not the fault of the other $50 \%$ that they are not also secure and comfortable with seeking help.

\section{Avoidant/Dismissive}

Typically, the avoidant/dismissive family is not a problem for doctors, unless they have a child who is seriously ill and parents are just not taking it seriously enough and are not consistent with attending appointments and sticking to treatment regimens. The typical response of many healthcare professionals in such cases is to become frustrated and tell parents off for not doing what needs to be done. Clearly, if there are serious concerns, a safeguarding referral should be made. However, in less severe cases, an authoritarian attitude will backfire and may well lead parents to disengage completely. The best advice is to remain unemotional and logical and explain to parents that by persevering with the advice, the child will need fewer hospital admissions and that this is time well spent. It may also help to print off information and talk about evidence-based practice. Any show of emotion is likely to put them off. They want to know that they are in 
charge and that you recognise that and that you are an expert who can advise, but it is up to them to decide if they want to listen to the advice or not. With these families, doctors will get the best results by portraying themselves as equals, who can provide expert advice, but that the families obviously have the right and responsibility to take the advice or to leave it. This helps parents think logically and agree to treatment plans, which they are unable to do if they are emotionally aroused.

\section{Anxious/Preoccupied}

The family with insecure anxious/preoccupied attachment styles are likely to be difficult in that they present their child with minor complaints unnecessarily and are not easily reassured. The usual response of doctors is to be annoyed at their time being wasted and at families being 'needy' or 'clingy'. This often leads to doctors not wanting to see these families and doing whatever they can to evade them. Unfortunately, any degree of avoidance from a doctor will lead to an increase in help-seeking behaviour, as these families do not believe that they can manage on their own and feel totally dependent on the all-mighty doctor who can save them if only they were always available. A parent like this may initially make doctors feel good and useful, but later on they may feel as if there is never an end to the amount of time and/or interventions they require. It is important to note that the best way to treat these patients is counterintuitive. Many doctors will feel a strong urge to flee and to avoid the patient. However, this impulse needs to be suppressed. The best response is to be available, and in order to make this manageable, to schedule regular appointments. The time frame will vary on the setting - it can be a nurse visit every $20 \mathrm{~min}$ for inpatients or monthly outpatient appointments. The trick is to provide pre-emptive predictable care, independent of the patient's (unnecessary) distress signals. The aim is to help the patient understand that they will get good care independent of their requests or demands. Regular appointments will eventually be time-effective as these families learn to be very good at escalating the concerns and forcing emergency or urgent appointments if they are not seen when they feel they need to be. It can help to think of these parents as people who want the best for their child, but do not believe themselves that they are able to provide it and they therefore cling to the doctor as saviour. Providing regular predictable input, even if it is not that often, will go a long way to allaying their anxiety. The key is the regularity and dependability of contact, which will lessen their distress and consequent help-seeking.

\section{Disorganised/Fearful}

By far the most difficult doctor-patient relationships to deal with are those where disorganised/fearful attachments predominate. These parents and children have no trust in anyone and fully expect to be abused or neglected. They do not believe that they are worthy of help or that doctors are able or willing to help them. Unfortunately, this can result in a self-fulfilling prophecy, where they do not access support that is available and often antagonise people who could have helped. As a doctor working with these families, it is very important to not take things personally. The reason that these families have problems with trust is because of their own experiences in childhood, not because of anything the doctor does or does not do. The patients typically do not know this and will act in ways that are blaming, demanding or scornful and disparaging of help that is provided. Also, these families will not thank professionals, as in their minds they have to keep doctors on their toes and thanking them would be letting them off the hook. Many paediatricians struggle with these families, and it can be very helpful to get a psychiatrist or other mental health professional involved, even if it is behind the scenes, to help staff process the difficult feelings that these patients engender in those who try to help them. It is very important to carefully consider whether thresholds are met for a safeguarding referral, as both abuse and neglect are more common in these scenarios. As for paediatricians, the best advice with these families is to not expect any gratitude and to not let critical comments affect them. It is helpful to stick to the usual standard of good care and to talk to other staff who are involved in order to blow off steam. It helps to think of these parents as people who are absolutely desperate for help, but who cannot bring themselves to trust anyone. They therefore fluctuate between the avoidant and anxious styles, and the best way for doctors to cope is to just do what they would have done for a family with secure attachments and to not let themselves be swayed to do either too much or too little.

\section{CONCLUSION}

Parents who are 'difficult' have not chosen to be that way. We are all very much a product of our genes and environment. As professionals, we therefore need to guard against compounding the difficult lives our patients have by adding to that through knee-jerk behaviours that may be justified and understandable but are ultimately unhelpful. ${ }^{56} \mathrm{I}$ hope that the insights from the attachment theory will be helpful to paediatricians who are trying their best to help sick children who have parents who behave in difficult ways. Having the skill of using different communication styles to adapt to the needs of our patients and their parents will likely also improve our own resilience and well-being.

In all cases, keep safeguarding in mind, as we know that neglect, emotional, sexual and physical abuse of children are common and may be an underlying factor with the difficulties they present. ${ }^{7}$ 
Funding The authors have not declared a specific grant for this research from any funding agency in the public, commercial or not-for-profit sectors.

Competing interests None declared.

Provenance and peer review Commissioned; externally peer reviewed.

\section{REFERENCES}

1 Panzer A, Viljoen M, Maunder R, et al. The difficult patient: an attachment perspective. SA Fam Pract 2003;45:11-13.

2 Maunder RG, Panzer A, Viljoen M, et al. Physician's difficulty with patients is related to patient's attachment type. Social Sci Med 2006;63:552-62.

3 Frederiksen HB, Kragstrup J, Dehlholm-Lambertsen B. Attachment in the doctor-patient relationship in general practice: a qualitative study. Scand J Prim Health Care 2010;28:185-90.

4 Swanepoel A, Sieff DF, Music G, et al. How evolution can help us understand child development and behaviour. BJPsych Adv 2016;22:36-43.

5 Boland R. The 'problem patient': modest advice for frustrated clinicians. R I Med J 2014;97:29-32.

6 Hinchey SA, Jackson JL. A cohort study assessing difficult patient encounters in a walk-in primary care clinic, predictors and outcomes. J Gen Intern Med 2011;26:588-94.

7 World Health Organization, 2017. Child maltreatment. http:// www.who.int/violence_injury_prevention/violence/child/Child_ maltreatment_infographic_EN.pdf?ua =1 